\title{
Minimizing Response Time with Optimal Fire Station Allocation
}

\author{
Joon-Yeoul $\mathrm{Oh}^{1}$, Amir Hessami ${ }^{2}$, Hee Joong Yang ${ }^{3}$ \\ ${ }^{1}$ Mechanical and Industrial Engineering Department, Texas A\&M University-Kingsville, Kingsville, TX 78363, USA \\ ${ }^{2}$ Civil and Architectural Engineering Department, Texas A\&M University-Kingsville, Kingsville, TX 78363, USA \\ ${ }^{3}$ Industrial Engineering Department, Cheong-Ju University, Cheong-Ju, Korea \\ Correspondence: Joon-Yeoul Oh, Mechanical and Industrial Engineering Department, Texas A\&M University- \\ Kingsville, 700 University Blvd. Kingsville, TX 78363, USA.
}

Received: April 1, 2019 Accepted: May 7, 2019 Online Published: May 9, 2019

doi:10.11114/set.v6i1.4187

URL: https://doi.org/10.11114/set.v6i1.4187

\begin{abstract}
Quick response time in emergency situation is critical to protect human lives. In the fast-growing cities, fire departments can fall behind the standard response time due to cities' expansion. This research focuses on ways to improve the response time of a city's emergency situation. A Non-linear Programming model is used to determine the locations of fire stations, so that they can cover the maximum number of residents, in terms of the geographical area and population. The model is applied to the city of Kingsville, Texas to check the practicability. The results of the research indicate that optimized locations make population coverage increment up to $15 \%$ and geographic coverage increment up to $21 \%$ with two fire stations. With three fire stations including a newly added fire station, the population coverage goes up to $48 \%$ increment and the geographic coverage increased up to $71 \%$, which covers $88 \%$ of total city population.
\end{abstract}

Keywords: emergency response time, fire station allocation, maximum coverage, optimal location

\section{Introduction}

Quick response by emergency personnel to fires and medical crises plays a vital role in saving lives. Proper allocation of emergency response centers such as fire stations plays an important role in reducing fatality rates of emergency incidents (Ko et al., 2014). According to U.S. Fire Administration (2018), fire is the leading cause of fatal accidents in the U.S. with 3,280 deaths and $\$ 14.3$ billion in property damages occurred by 1,345,500 fires in 2015. Fire departments in the U.S. are often the first to respond to any type of emergency, and they have played this role since the country's very beginning. The development of modern firefighting forces in the U.S. has created innovations that have spread across the world. Today's fire departments are the first-line responders against death and damage in nearly every community in America (Walker et al., 1975). The primary organization of firefighters in the U.S. is the National Fire Protection Association (NFPA), which was established in 1896 with the mission of eliminating or reducing death, injury, property damage, and economic loss due to fires and related hazards (NFPA, 2016). Regardless of what agency provides the ultimate medical transportation and treatment, the fire service is the agency in the U.S. that first delivers on-scene healthcare services under true emergency conditions. The speed with which fire personnel can react and initiate action is thus a very significant factor in creating better health outcomes and preventing property damage. The response time of emergency vehicles depends on the location of incidents and the fastest route to the destination. Fire service-based Emergency Management System (EMS) is strategically positioned to deliver time-critical responses and effective first-on-scene patient care.

The main objective of this research is to use Nonlinear Programming (NLP) modeling technique to define the optimal location of fire stations and thus minimize the response time for fire and medical emergencies. The city of Kingsville, TX, was used as a case study to show the viability of this technique. City of Kingsville is currently one of the fastest-growing cities in the U.S., and in recent years its fire departments have struggled to contend with significant increases in emergency calls.

The current average response time of the City of Kingsville Fire Department is 4 minutes and 32 seconds. This is roughly $13 \%$ slower than the recommended standards of the NFPA. The reason for this relatively slow average response-time is primarily the booming population of Kingsville, which has overrun the ability of the city's emergency services to keep up. Since the population growth of the city shows no signs of slowing, the issue is only likely to worsen 
in the future unless the city's ability to provide emergency services is expanded. Many fast growing cities face the same challenge and the modeling approach developed in this study can help them better manage their resources.

The city of Kingsville, similar to many other cities in the U.S., has a railroad passing through the center of town, which divides the city into two parts. When trains are present, these crossings can significantly delay emergency response vehicles if they are coming from the other side of the tracks. Therefore, these railroad crossings cannot be neglected in any response-time optimization analysis.

To achieve the objective of this research, first of all, the city of Kingsville was divided into 20 zones and the data, population and distances, is collected by each zone. Based on the data collected, the geographical coverage area and population coverage by the existing fire stations within the required response time are calculated. This research considered various scenarios, such as zone accessibility by railroad crossing, relocation of one or two stations, and impact of one additional station. For each scenario, the optimal locations were determined with maximum geographical coverage and population coverage.

\section{Literature Review}

The response time of fire agencies to get ready and carry equipment to the scene of an emergency at a particular time is critical. Figure 1 shows the activity chart of a fire emergency. According to the National Fire Protection Association (NFPA, 2016), the total Response Time (RT) can be defined from the time that a call is received by their emergency answering center to the arrival of the first emergency vehicle at the scene for the initiation of action.

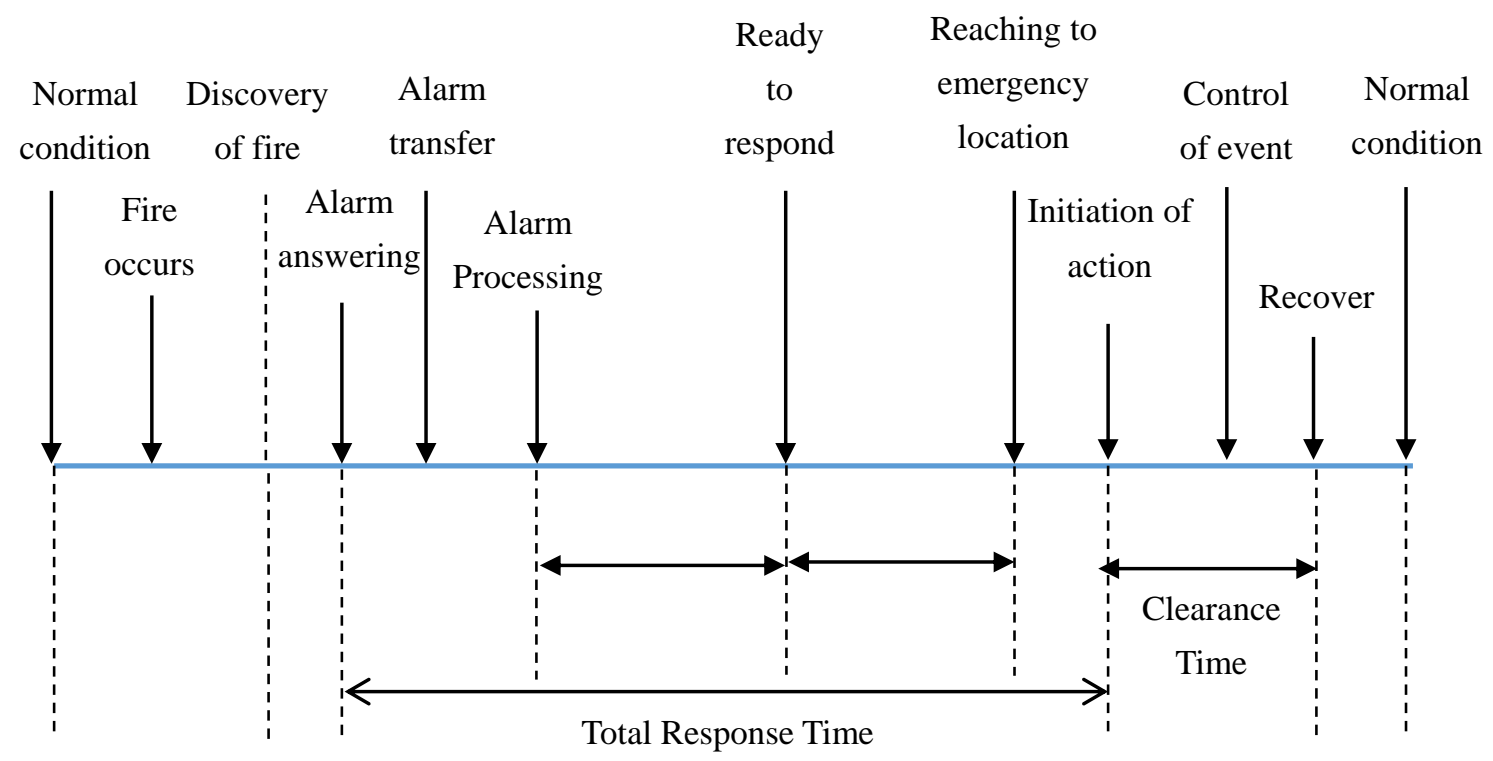

Figure 1. Cascading event chart for an emergency situation

Figure 1 shows the cascading event chart for an emergency situation. The total response time includes turnout time and travel (to the scene) time. The standard turnout time is the time from station-acknowledged notification of the emergency until the time the response equipment departs from the station (Fire Engineering, 2004). According to NFPA 1710 (NFPA, 2016), the response time should be less than 240 seconds with less than 80 seconds of the turnout time. Over the past few decades decision models have been developed for allocation of emergency facilities.

The Maximum Covering Location Problem (MCLP) is one of the most favored models for analyzing the positioning problem. Murray (2013), Marianov et al. (1996) and Galvao et al. (1996) proposed using the MCLP approach to position fire stations. These researches were to ensure that the maximum population would be covered by at least one of the facilities. This method considered two constraints; all residents must be suitably served within the standards of NFPA by one or more of the fire stations and no more than certain numbers (with upper limits) of fire stations can be allocated with available resources.

The simplest of all covering problem approaches is the Location Set Covering Problem (LSCP), which seeks to minimize the number of facilities that are required to cover a specific area (Revelle et al., 1989). The P-center problem is a very similar type of model, which seeks to locate a certain number of facilities in a way that covers the maximum amount of residents within the study area (Galvao et al., 1996).

BCLP (Backup Covering Location Problem) is another approach that has been used in addition to LSCP and MCLP. 
BCLP is a multi-objective mathematical function. In this approach the first objective is to maximize the total demand covered, and the second objective is to maximize total demand receiving coverage by two or more facilities (Murray et al., 2010). Liu et al. (2006) developed an approach to optimizing the location of fire stations using a multi-objective model. In this approach three objectives were posited: maximizing the coverage of uncovered routes, achieving the reasonable distance between two fire stations, and maximizing the area served within the standard response time. Kwan et al. (2005) described how the response time is increased in an urban areas due to the impact of an emergency on the immediate environment at the street level.

The group decision-making process is another technique that has been adopted to reduce response time by mapping fire station in a metropolitan city (Chaudhry et al., 2016). Factors such as land cover, distance from rivers, population density, and distance from roads are considered in the analysis as factors that affect the response time.

Various allocation models have been developed to address the problem of multiple simultaneous fire occurrences, such as first in/first out (FIFO), nearest territory, and the highest priority based on incident severity (Ozbay et al., 2003). Using discrete event simulation modeling, target areas for improvement have been identified including optimized process flow, resource allocation, and operational policies (Chongsun et al., 2016). Other researcher has developed a model based on a generalized assignment model (Fisher et al., 1986).

Schilling et al. (1980) and Badri et al. (1998) developed a complicated multi-objective location analysis that included 11 strategic objectives along with several system constraints. The constraints include monetary, demand, distance, time, target, overlapping, and water availability. These researchers added the additional objectives to an existing model to increase its details and performance. The main goal in this approach is to maximize fire engine coverage and a secondary goal is to maximize fire truck coverage. Lai et al. (2012) used genetic algorithm along with Bender's decomposition technique to solve the problem of vehicle routing problem. This combination helps to enhance the computation efficiency.

Apart from coverage problem research, additional studies have been carried out on operational problems related to the deployment of emergency vehicles. Queuing models and probabilistic demand models are the most common analyses in these operational contexts (Green et al., 2017).

\section{Model Development}

To develop the NLP models for the optimal operations, in terms of the maximum coverage area within the standard RT and the maximum population coverage, in cases of emergency, first of all, the geographical coverage and population coverage by the current operation within the standard response time are calculated. Based on the data obtained by current operation, various mathematical models are made for different scenarios, including railway constraints and population constraints.

\subsection{Assumptions for the Models}

Several assumptions were made in the mathematical models.

- Average emergency vehicle speed of $30 \mathrm{mph}$ was assumed.

- For each roadway turn 90 degree left or right (every turning point) on the way to an emergency location, an additional 3.5 seconds was added to the estimated travel time.

- Railway crossings were considered to be prohibitive (i.e. closed), so that a fire station can only access the city area on the same side of the tracks as its own location.

- Emergency calls are proportional to the population.

- Minimum distance with nearing fire station is 1.5 miles. This ensures that the fire station can cover area with minimum overlapping coverage.

Because the maximum travel distance in case of emergency to meet the standard RT is about 1.3 miles, the minimum distance between each station is assumed 1.5 miles. The city of Kingsville was divided into 20 different geographic zones, and data for each zone was collected, including total population, population density, and number of households (Onboard Informatics, 2018). The current location of the city's fire stations resulted in average response time of 4 minutes 32 seconds; the goal of our analysis was to improve that time so that all or majority of responses were within the NFPA-recommended standard of 4 minutes. To reduce the response time, multiple possible scenarios were created and NLP models were developed for each scenario to estimate the average response time, land coverage, and population covered.

\subsection{Coverage area within the Standard Response Time from Current Locations}

To estimate the coverage of fire departments a simple distance formula is used. The method to find the area of overlapping regions is somewhat more complex. The following indices and parameters are used for the model. 
n Number of zones in Kingsville city. Data were collected in 20 zones.

m Number of fire stations.

i Index for zones of Kingsville city $(i=1,2,3, \ldots \ldots, n)$.

$\mathrm{j} \quad$ Index for fire stations $(\mathrm{j}=1,2, \ldots \mathrm{m})$.

Ts Standard response time from NFPA 1710.

To Turnout time according to NFPA 1710.

$\mathrm{Tt}$ Travel time of emergency vehicle.

Vavg Average vehicle speed.

Dact Actual distance covered by the fire station.

$\Delta \quad$ Minimum distance between neighboring fire stations. 1.5 miles was used in this research.

Wi Weight based on the population of zone $\mathrm{i}$.

$\mathrm{Cj}$ Binary value for railway constraint. 1 for the fire station $\mathrm{j}$ is available to access; 0 for not available due to a train passing.

$\mathrm{xj} \quad$ Latitude of location of fire station $\mathrm{j}$.

yj Longitude of location of fire station $j$.

The total response time is always greater than the sum of the turnout time and the travel time, then To $+\mathrm{Tt} \leq \mathrm{Ts}$. According to NFPA 1710 response time (Ts) of 240 seconds and 80 seconds of the turnout time (To), the total travel time to meet the standard RT would be less than 160 seconds (NFPA, 2016).

The velocity can be defined as Velocity = Distance / Time, and applying the assumption of average speed of $30 \mathrm{mph}$, the maximum distance that an emergency vehicle can travel within the standard time is 1.3333 miles. Based on this distance calculation, the maximum area coverage of the City of Kingsville's current fire stations can be found. The following Figure 2 shows the area of coverage within the NFPA's recommended response time for the current fire station locations. The circle on the right in the Figure 2 indicates the covering area of the primary (head quarter) fire station. The circle on left in the Figure 2 shows the covering area of the branch station. As seen in the Figure 2, there is a large overlapped region in the city's fire coverage, where both stations are within the 4-minute response time for some residents.

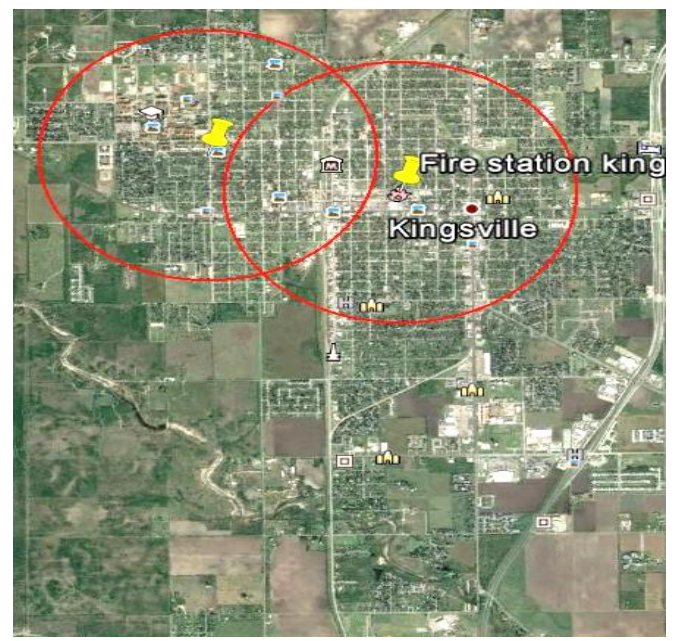

Figure 2. City of Kingsville fire station locations and their coverage with standard response time

To calculate the total geographic area of coverage, it is assumed that the coverage area for each station has the same radius: $\quad \Pi R^{2}+\Pi R^{2}=2 \times \Pi R^{2}$. However, this calculation includes overlapped region twice as seen in the Figure 3. Thus, any overlapped region was subtracted from the total. In order to calculate the area of the overlapped region a "double lens" approach was used. Figure 3 shows two circles of equal radius $\mathrm{R}$ and with distance $\mathrm{d}$ between their two centers. 


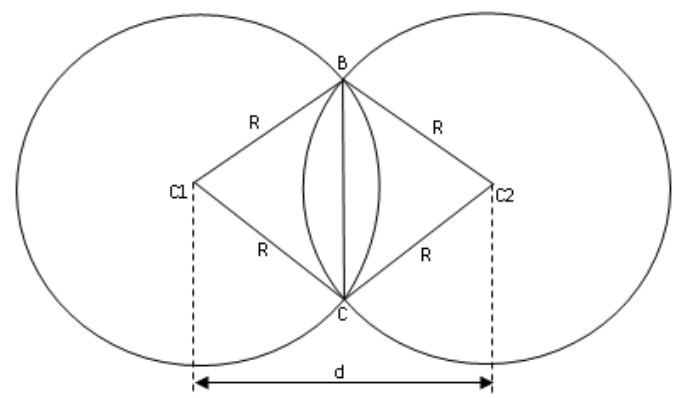

Figure 3. Overlapping circle geometry

Figure 4 shows the sector of circle, and the area of the overlap is calculated as, area of sector $=\frac{\theta}{2} * R^{2}$.

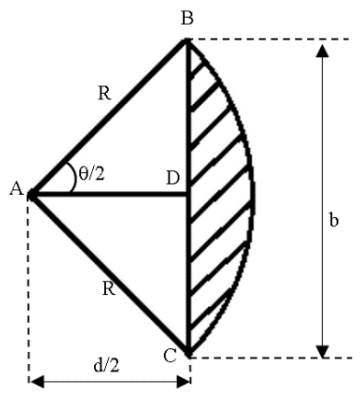

Figure 4. Sector of circle

Since the area of half lens $=$ Area of sector of circle - Area of $\triangle \mathrm{ABC}$, the area of half lens (overlapped area) becomes

$$
R^{2} * \cos ^{-1} \frac{d}{2 R}-\frac{d}{4} \times \sqrt{4 R^{2}-d^{2}}
$$

The total area of overlapped region $=2 \times$ area of half lens, so

$$
\begin{gathered}
=2 \times\left(R^{2} \times \cos ^{-1} \frac{d}{2 R}-\frac{d}{4} \times \sqrt{4 R^{2}-d^{2}}\right) \\
=2 R^{2} \times \cos ^{-1} \frac{d}{2 R}-\frac{d}{2} \times \sqrt{4 R^{2}-d^{2}}
\end{gathered}
$$

Hence, area covered by 2 fire stations $=2 \times \Pi R^{2}$ - Total area of overlapped region becomes

$$
2 \times \Pi R^{2}-2 R^{2} \times \cos ^{-1} \frac{d}{2 R}-\frac{d}{2} \times \sqrt{4 R^{2}-d^{2}}
$$

For general, area covered by $\mathrm{n}$ number of fire stations $=\mathrm{n} * \Pi R^{2}$ - Total area of overlapped region. This formula is applied to calculate the city's area coverage, which is 3.76 square miles. This is about $27.056 \%$ of total Kingsville city size, 13.9 sq. miles. The population covered at the 4-minute response time by current locations is $59.088 \%$, which is about 15,000 out of the total 26,058 individuals.

The city of Kingsville fire departments received 3202 emergency calls per year. This is about 123 calls per every 1000 people. Based on this data, the number of calls for each zone is estimated as following Table 1. 
Table 1. Weighted value for each zone

\begin{tabular}{|c|c|c|c|c|c|}
\hline Zone \# & Population & $\begin{array}{l}\text { Number of } \\
\text { households }\end{array}$ & $\begin{array}{c}\text { Expected } \\
\text { number of calls }\end{array}$ & $\begin{array}{c}\text { Portion of } \\
\text { calls }\end{array}$ & $\begin{array}{l}\text { Weighted } \\
\text { value }\end{array}$ \\
\hline Zone 1 & 1778 & 764 & 218 & 2 & $2 / 33$ \\
\hline Zone 2 & 112 & 31 & 14 & 0 & 0 \\
\hline Zone 3 & 771 & 322 & 95 & 1 & $1 / 33$ \\
\hline Zone 4 & 1535 & 601 & 188 & 2 & $2 / 33$ \\
\hline Zone 5 & 877 & 290 & 108 & 1 & $1 / 33$ \\
\hline Zone 6 & 1931 & 343 & 237 & 2 & $2 / 33$ \\
\hline Zone 7 & 1421 & 391 & 175 & 2 & $2 / 33$ \\
\hline Zone 8 & 1406 & 611 & 173 & 2 & $2 / 33$ \\
\hline Zone 9 & 1483 & 884 & 182 & 2 & $2 / 33$ \\
\hline Zone 10 & 1267 & 499 & 156 & 1 & $1 / 33$ \\
\hline Zone 11 & 1790 & 607 & 220 & 2 & $2 / 33$ \\
\hline Zone 12 & 601 & 334 & 74 & 1 & $1 / 33$ \\
\hline Zone 13 & 426 & 108 & 53 & 1 & $1 / 33$ \\
\hline Zone 14 & 680 & 308 & 84 & 1 & $1 / 33$ \\
\hline Zone 15 & 1289 & 568 & 158 & 2 & $2 / 33$ \\
\hline Zone 16 & 1878 & 647 & 231 & 2 & $2 / 33$ \\
\hline Zone 17 & 696 & 398 & 85 & 1 & $1 / 33$ \\
\hline Zone 18 & 1536 & 834 & 189 & 2 & $2 / 33$ \\
\hline Zone 19 & 3268 & 1219 & 401 & 4 & $4 / 33$ \\
\hline Zone 20 & 1313 & 571 & 161 & 2 & $2 / 33$ \\
\hline Total & 26,058 & 10,330 & 3202 & 33 & \\
\hline
\end{tabular}

The portion of emergency calls for each zone is calculated by dividing expected number of calls by 100 and converting it to its nearest integer for the analysis. For example, in zone 1, the estimated number of emergency calls is 218 and divide by 100 becomes 2.18 . So, nearest integer 2 is assigned. The weighted value (Wi) of each zone is calculated by dividing each portion of calls by total sum of portions.

\subsection{NLP Models for Two Fire Stations}

There are i potential zones to cover by $\mathrm{j}$ fire station, and the response time should be less than or equal to the standard response time of NFPA, which is a 4 minutes. The response time can be minimized by relocating the current fire stations. To make model more accurately, the reallocation of the fire stations should consider the constraints, such as boundary limitations, minimum distance between neighboring fire stations, railway crossings, and population constraints.

In this model, the number of zones (n) considered is 20 , and the number of fire stations (m) is 2 . Let (x1, y1) and (x2, y2) be the locations of two fire stations, then the following formula (5) shows the general NLP model to minimize distances from the fire stations to each zone.

$$
\operatorname{Min} C 1 \times \sum_{i=1}^{n} \frac{W i}{n} \times \sqrt{(x i-x 1)^{2}+(y i-y 1)^{2}}+C 2 \times \sum_{i=1}^{n} \frac{W i}{n} \times \sqrt{(x i-x 2)^{2}+(y i-y 2)^{2}}
$$

$\mathrm{C} 1$ and $\mathrm{C} 2$ are the binary variables and used for the railway crossing constraint, which means that the fire station can access only locations that are on its own side of the railway. These values are 1 if a location is on the same side of the railway as the fire station, and 0 for those areas on the other side of the railway from the fire stations. This objective function is subjected to the following constraints, city boundaries and minimum distance for nearing fire stations. Because travel distance for emergency is about 1.3 miles, as seen in the model assumption section, the minimum distance $(\Delta)$ between each fire station is set to 1.5 miles. For the boundary limits, the values are expressed in longitudes 
and latitudes. Formula (6) shows the mathematical model with two fire stations.

$$
\operatorname{Min} C 1 \times \sum_{i=1}^{n} \frac{W i}{n} \times \sqrt{(x i-x 1)^{2}+(y i-y 1)^{2}}+C 2 \times \sum_{i=1}^{n} \frac{W i}{n} \times \sqrt{(x i-x 2)^{2}+(y i-y 2)^{2}}
$$

\section{Subject to}

$$
\begin{aligned}
& x 1, x 2 \geq \text { Lower boundary of Latitude } \\
& x 1, x 2 \leq \text { Upper boundary of Latitude } \\
& y 1, y 2 \geq \text { Lower boundary of Longitude } \\
& y 1, y 2 \leq \text { Upper boundary of Longitude } \\
& \sqrt{(x 1-x 2)^{2}+(y 1-y 2)^{2}} \geq \Delta
\end{aligned}
$$

Wi is 1 when the population constraint is not used (i.e. all zones are considered as equally populated). When population densities vary, this variable takes a weighted value. Considering all railway and population constraints, 8 scenarios were developed.

- Scenario 1.1: Relocation of primary fire station considering all zones equally populated and without considering railway constraint. $(\mathrm{C} 1=1, \mathrm{C} 2=0, \mathrm{Wi}=1)$

- Scenario 1.2: Relocation of primary fire station considering all zones differently populated and without considering railway constraint. $(\mathrm{C} 1=1, \mathrm{C} 2=0, \mathrm{Wj}=$ value based on population $)$

- Scenario 1.3: Relocation of both fire stations considering all zones equally populated and without considering railway constraint. $(\mathrm{C} 1=1, \mathrm{C} 2=1, \mathrm{Wi}=1)$

- Scenario 1.4: Relocation of both fire stations considering all zones differently populated and without considering railway constraint. $(\mathrm{C} 1=1, \mathrm{C} 2=1, \mathrm{Wi}=$ value based on population $)$

- Scenario 1.5: Relocation of primary fire station considering all zones equally populated and with a railway constraint. $(\mathrm{C} 1=1, \mathrm{C} 2=0, \mathrm{Wi}=1)$

- Scenario 1.6: Relocation of primary fire station considering all zones differently populated and with a railway constraint. $(\mathrm{C} 1=1, \mathrm{C} 2=0, \mathrm{Wi}=$ value based on population $)$

- Scenario 1.7: Relocation of both fire stations considering all zones equally populated and with a railway constraint. $(\mathrm{C} 1=1, \mathrm{C} 2=1, \mathrm{Wi}=1)$

- Scenario 1.8: Relocation of both fire stations considering all zones differently populated and with a railway constraint. $(\mathrm{C} 1=1, \mathrm{C} 2=1, \mathrm{Wi}=$ value based on population $)$

\subsection{NLP Models for Three Fire Stations}

Because the city of Kingsville's residential areas are geographically widespread, two fire stations cannot cover all the zones. So, one additional station will give wider coverage of response time. In this model, the number of zones (n) considered is 19 , and the number of fire stations $(\mathrm{m})$ is 3 . The objective is to minimize distances from the fire stations to each zone.

$$
\operatorname{Min} \sum_{i=1}^{n} \sum_{j=1}^{m} C j \times \frac{W i}{n} \times \sqrt{(x i-x j)^{2}+(y i-y j)^{2}}
$$

Similar to the two fire station model, $\mathrm{Cj}$ is used for the railway constraint, indicating whether or not an area is on the same side of the railroad tracks as the fire station. Wi is 1 when the population constraint is not used (i.e. all zones are considered as equally populated). When population densities vary, this variable takes a weighted value. This objective function is subjected to the constraints, such as upper and lower boundary limits and distances between each station. Formula (8) shows the mathematical model with three fire stations. 


$$
\text { Min } \quad C 1 \times \sum_{i=1}^{n} \frac{W i}{n} \times \sqrt{(x i-x 1)^{2}+(y i-y 1)^{2}}+C 2 \times \sum_{i=1}^{n} \frac{W i}{n} \times \sqrt{(x i-x 2)^{2}+(y i-y 2)^{2}}
$$

Subject to

$$
\begin{aligned}
& x 1, x 2, x 3 \geq \text { Lower boundary of Latitude } \\
& x 1, x 2, x 3 \leq \text { Upper boundary of Latitude } \\
& y 1, y 2, y 3 \geq \text { Lower boundary of Longitude } \\
& y 1, y 2, y 3 \leq \text { Upper boundary of Longitude } \\
& \sqrt{(x 1-x 2)^{2}+(y 1-y 2)^{2}} \geq \Delta \\
& \sqrt{(x 1-x 3)^{2}+(y 1-y 3)^{2}} \geq \Delta \\
& \sqrt{(x 3-x 2)^{2}+(y 3-y 2)^{2}} \geq \Delta
\end{aligned}
$$

Thus, in considering all railway and population constraints there are also 8 scenarios.

- Scenario 2.1: Constructing a new fire station without changing current locations, without a railway constraint, considering equally populated zones.

- Scenario 2.2: Constructing a new fire station without changing current locations, without a railway constraint, considering differently populated zones.

- Scenario 2.3: Constructing a new fire station while also changing current locations, without a railway constraint, considering equally populated zones.

- Scenario 2.4: Constructing a new fire station while also changing current locations, without a railway constraint, considering differently populated zones.

- Scenario 2.5: Constructing a new fire station without changing current locations, with a railway constraint, considering equally populated zones.

- Scenario 2.6: Constructing a new fire station without changing current locations, with a railway constraint, considering differently populated zones.

- Scenario 2.7: Constructing a new fire station while also changing current locations, with a railway constraint, considering equally populated zones.

\begin{tabular}{|c|c|c|c|c|}
\hline Cases & Subcases & $\begin{array}{l}\text { Population } \\
\text { density }\end{array}$ & $\begin{array}{l}\% \text { of area } \\
\text { covered }\end{array}$ & $\begin{array}{l}\% \text { increase in } \\
\text { area covered }\end{array}$ \\
\hline \multirow{4}{*}{$\begin{array}{l}\text { Without } \\
\text { railway } \\
\text { constraint }\end{array}$} & \multirow{2}{*}{$\begin{array}{l}\text { Relocation of primary } \\
\text { fire station }\end{array}$} & Equal density & $30.275 \%$ & $11.898 \%$ \\
\hline & & Varied density & $30.096 \%$ & $11.236 \%$ \\
\hline & \multirow{2}{*}{$\begin{array}{l}\text { Relocation of both fire } \\
\text { stations }\end{array}$} & Equal density & $30.093 \%$ & $11.225 \%$ \\
\hline & & Varied density & $30.548 \%$ & $12.907 \%$ \\
\hline \multirow{4}{*}{$\begin{array}{l}\text { With railway } \\
\text { constraint }\end{array}$} & \multirow{2}{*}{$\begin{array}{l}\text { Relocation of primary } \\
\text { fire station }\end{array}$} & Equal density & $30.259 \%$ & $11.838 \%$ \\
\hline & & Varied density & $31.121 \%$ & $15.024 \%$ \\
\hline & \multirow{2}{*}{$\begin{array}{l}\text { Relocation of both fire } \\
\text { stations }\end{array}$} & Equal density & $30.275 \%$ & $11.898 \%$ \\
\hline & & Varied density & $30.096 \%$ & $11.236 \%$ \\
\hline
\end{tabular}

- Scenario 2.8: Constructing a new fire station while also changing current locations, with a railway constraint, considering differently populated zones.

\section{Results Analysis}

Microsoft Excel Solver was used to solve these models for each scenario to determine the optimal current locations for the City of Kingsville's fire stations. The maximum possible benefits that were found using the NLP analysis for Scenario 1 (two fire stations) are presented in Tables 2.

Table 2. Area Coverage within the standard RT for Two Fire Stations case 
The response time from fire stations to the center of each zone is calculated. Table 3 shows the average response time with two fire stations. All cases satisfy the standard RT except one case, 1.3.

Table 3. Average Response Time for Two Fire Stations case

\begin{tabular}{cc}
\hline Scenarios & Average response time \\
\hline Current & 272 seconds \\
\hline 1.1 & 230.32 seconds \\
\hline 1.2 & 224.54 seconds \\
\hline 1.3 & 289.84 seconds \\
\hline 1.4 & 221.05 seconds \\
\hline 1.5 & 225.80 seconds \\
\hline 1.6 & 224.96 seconds \\
\hline 1.7 & 230.32 seconds \\
\hline 1.8 & 224.54 seconds \\
\hline
\end{tabular}

The findings indicate that with two fire stations scenarios, the total coverage area for the residents within the NFPA standard response time can be increased up to $15 \%$ above the current coverage while still only using two fire stations. The difference in results between the cases where equal population density was assumed and the case where differences in population density was incorporated into the calculation demonstrates the tremendous importance of this variable. The results also show that if the varied density is considered, the locations of the fire stations can be much better optimized as seen in Tables 4.

Table 4. Population coverage for Two Fire Stations case

\begin{tabular}{cccc}
\hline Scenarios & $\begin{array}{c}\text { Population } \\
\text { covered }\end{array}$ & $\begin{array}{c}\text { \% of population } \\
\text { covered }\end{array}$ & $\begin{array}{c}\text { \% change in } \\
\text { population covered }\end{array}$ \\
\hline Current & 15397 & $59.088 \%$ & $0.000 \%$ \\
\hline 1.1 & 18480 & $70.919 \%$ & $20.023 \% \uparrow$ \\
\hline 1.2 & 18631 & $71.504 \%$ & $21.013 \% \uparrow$ \\
\hline 1.3 & 9166 & $35.178 \%$ & $40.465 \% \downarrow$ \\
\hline 1.4 & 18806 & $72.175 \%$ & $22.148 \% \uparrow$ \\
\hline 1.5 & 17859 & $68.541 \%$ & $15.998 \% \uparrow$ \\
\hline 1.6 & 18230 & $69.965 \%$ & $18.408 \% \uparrow$ \\
\hline 1.7 & 18480 & $70.924 \%$ & $20.031 \% \uparrow$ \\
\hline 1.8 & 18631 & $71.504 \%$ & $21.013 \% \uparrow$
\end{tabular}

For the scenarios with three fire stations, a much greater portion of Kingsville residents will fall within the NFPA-recommended 4-minute response time. The results for these scenarios are presented in Tables 5, 6 and 7. Table 5 shows the percentage of area covered within the standard RT. The results of all cases shows a great improvement of coverage area with the maximum of about $71 \%$ increment.

Table 5. Area Coverage within the standard RT for Three Fire Stations case

\begin{tabular}{|c|c|c|c|c|}
\hline Cases & Subcases & $\begin{array}{l}\text { Population } \\
\text { density }\end{array}$ & $\begin{array}{l}\% \text { of area } \\
\text { covered }\end{array}$ & $\begin{array}{l}\% \text { increase in } \\
\text { area covered }\end{array}$ \\
\hline \multirow{4}{*}{$\begin{array}{l}\text { Without railway } \\
\text { constraint }\end{array}$} & \multirow{2}{*}{$\begin{array}{l}\text { Without changing } \\
\text { current locations }\end{array}$} & Equal density & $42.351 \%$ & $56.531 \%$ \\
\hline & & Varied density & $42.218 \%$ & $56.039 \%$ \\
\hline & \multirow{2}{*}{$\begin{array}{l}\text { With changing } \\
\text { current locations }\end{array}$} & Equal density & $44.599 \%$ & $64.840 \%$ \\
\hline & & Varied density & $44.600 \%$ & $64.843 \%$ \\
\hline \multirow{4}{*}{$\begin{array}{l}\text { With railway } \\
\text { constraint }\end{array}$} & \multirow{2}{*}{$\begin{array}{l}\text { Without changing } \\
\text { current locations }\end{array}$} & Equal density & $39.408 \%$ & $38.261 \%$ \\
\hline & & Varied density & $42.164 \%$ & $55.840 \%$ \\
\hline & \multirow{2}{*}{$\begin{array}{l}\text { With changing } \\
\text { current locations }\end{array}$} & Equal density & $46.425 \%$ & $71.589 \%$ \\
\hline & & Varied density & $45.312 \%$ & $67.475 \%$ \\
\hline
\end{tabular}

Table 6 shows the average response time of each cases with three stations. The results of all cases with three stations show less average response time than the current one. All of these average response times are less than the standard RT, 240 seconds. 
Table 6. Average Response Time for Three Fire Stations case

\begin{tabular}{cc}
\hline Scenarios & Average response time \\
\hline Current & 272 seconds \\
\hline 2.1 & 222.50 seconds \\
\hline 2.2 & 222.01 seconds \\
\hline 2.3 & 216.68 seconds \\
\hline 2.4 & 212.13 seconds \\
\hline 2.5 & 221.74 seconds \\
\hline 2.6 & 221.19 seconds \\
\hline 2.7 & 214.97 seconds \\
\hline 2.8 & 211.76 seconds
\end{tabular}

Table 7 shows the population coverage within the standard RT. The results shows that the population coverage is increased in all cases with three fire stations.

Table 7. Population coverage comparison for Three Fire Stations case

\begin{tabular}{cccc}
\hline Scenarios & $\begin{array}{c}\text { Population } \\
\text { covered }\end{array}$ & $\begin{array}{c}\text { \% of population } \\
\text { covered }\end{array}$ & $\begin{array}{c}\text { \% change in } \\
\text { population covered }\end{array}$ \\
\hline Current & 15397 & $59.088 \%$ & $0.000 \%$ \\
\hline 2.1 & 19180 & $73.610 \%$ & $24.577 \% \uparrow$ \\
\hline 2.2 & 20900 & $80.212 \%$ & $35.750 \% \uparrow$ \\
\hline 2.3 & 19586 & $75.169 \%$ & $27.215 \% \uparrow$ \\
\hline 2.4 & 19674 & $75.507 \%$ & $27.787 \% \uparrow$ \\
\hline 2.5 & 21639 & $83.048 \%$ & $40.549 \% \uparrow$ \\
\hline 2.6 & 21815 & $83.724 \%$ & $41.694 \% \uparrow$ \\
\hline 2.7 & 22199 & $85.197 \%$ & $44.187 \% \uparrow$ \\
\hline 2.8 & 22884 & $87.826 \%$ & $48.635 \% \uparrow$ \\
\hline
\end{tabular}

These results indicate that the use of 3 fire stations can decrease average response time by roughly ten seconds, while also greatly expanding the percentage, up to $48 \%$ increment, of the city's residents who are covered with a 4-minute standard response time.

\section{Conclusion and Discussion}

Emergency includes natural disasters, car accident, health emergency, building fire and many more. Emergency services of fire department such as ambulance, fire truck or fire engine are equipped with necessary tools and personnel to deal with those emergencies. In the city of Kingsville, the average response time with current fire stations is 4 min 32 sec which is 272 seconds. According to NFPA 1710 response time should be within 4 min or 240 seconds.

The objective of this research is to minimize average response time using NLP technique. The combinations of constraints, such as railway constraint, population constraint and minimum distance between two fire stations, are used for NLP models. To check usability of models different cases are created with two main scenarios; for 2 fire stations and for 3 fire stations.

The results of this research for the case of 2 fire stations shows that the coverage area can be increased up to $15 \%$ and the population coverage can be increased up to $21 \%$ with 2 fire stations if the stations are relocated. Two fire stations cases show that relocating 2 stations still cannot cover some zones. Therefore, one more fire station is added to see how much of area can be covered with one additional fire stations. The results with 3 fire stations cases show that around $88 \%$ of Kingsville population can be reached within the standard RT. This population coverage is about $48 \%$ of increment compared with current operation, which is about $59 \%$ population coverage, and at least $71 \%$ increment of the geographical area coverage compared with current coverage, which is about $27 \%$.

The research has raised few questions that need to be answered in future. The best location for fire stations can be found, but the research should be continued for the costs related to the relocation of fire stations and/or building new fire station. The objective of the mathematical models, considering cost of relocation, still should be the optimal covering 
area satisfying the standard RT, but the public safety and cost analysis should be included in the constraints to make the models more realistic.

\section{Acknowledgements}

The authors would like to acknowledge the contributions of Rutang Vijaykumar Shah, a graduate Industrial Engineering major student at the time this research was initiated.

\section{References}

Badri, M. A., Mortagy, A. K., \& Alsayed, C. A. (1998). A multi-objective model for locating fire stations. European journal of operation research, 110(2), 243-260. https://doi.org/10.1016/S0377-2217(97)00247-6

Chaudhry, P., Chhetri, S. K., Joshi, K. M., Shrestha N. M., \& Kayastha, P. (2016). Application of an analytic Hierarchy Process in the GIS interface for suiable fire site selection: A case study for Kathmandu metropolitan city. Socio-economic planning sciences, 53(9), 60-71. https://doi.org/10.1016/j.seps.2015.10.001

Chongsun, O., April, N. M., Pamela, C. L., Ray, R. K., Diane, C. D., \& Maureen, L. C. (2016). Use of a simulation-based decision support tool to improve emergency department throughput. Operations research for health care, 9(1), 29-39. https://doi.org/10.1016/j.orhc.2016.03.002

Fire Engineering. (2004). Turnout time. Retrieved from https://www.fireengineering.com/articles/print/volume-157/issue-7/departments/roundtable/turnout-time.html

Fisher, M. L., Jaikumar, R., \& Wassenhove, L. N. V. (1986). A multiplier adjustment method for the generalized assignment problem. Management science, 32(9), 1095-1102. https://doi.org/10.1287/mnsc.32.9.1095

Galvao, R. D., \& Revelle, C. (1996). A Lagrangean heuristic for the maximal covering location problem. European Journal of operational research, 88(1), 114-123. https://doi.org/10.1016/0377-2217(94)00159-6

Green, L. V., \& Kolesar, P. J. (2017). Improving emergency responsiveness with management science. Management Science, 50(8), 1001-1014. https://doi.org/10.1287/mnsc.1040.0253

Ko, Y. D., Song, B. D., Morrison, R. J., \& Hwang, H. (2014). Location Design For Emergency Medical Centers Based On Category of Treatable Medical Diseases and Center Capability. International Journal of Industrial Engineering: Theory, Applications and Practice, 21(3), 117-128.

Kwan, M. P., \& Lee, J. (2005). Emergency response after 9/11: the potential of real time 3D GIS for quick emergency response in micro-spatial environments. Computers, environment and urban systems, 29(2), 93-113. https://doi.org/10.1016/j.compenvurbsys.2003.08.002

Lai, M. C., Sohn, H. S., Tseng, T. L., \& Bricker, L. D. (2012). A Hybrid Benders/Genetic Algorithm for Vehicle Routing and Scheduling Problem. International Journal of Industrial Engineering: Theory, Applications and Practice, $19(1), 33-46$.

Liu, N., Huang, B., \& Chandramouli, M. (2006). Optimal siting of fire stations using GIS and ANT algorithm. Journal of computing in civil engineering, 20(5), 361-369. https://doi.org/10.1061/(ASCE)0887-3801(2006)20:5(361)

Marianov, V., \& ReVelle, C. (1996). The Queueing Maximal Availability Location Problem: A model for the siting of emergency vehicles. European journal of operation research, 93(1), 110-120. https://doi.org/10.1016/0377-2217(95)00182-4

Murray, A. T. (2013). Optimizing the spatial location of urban fire stations. Fire safety journal, 62(1), 64-71. https://doi.org/10.1016/j.firesaf.2013.03.002

Murray, A. T., Tong, D., \& Kim, K. (2010). Enhancing Classic Coverage Location Models. International regional science review, 33(2), 115-133. https://doi.org/10.1177/0160017609340149

NFPA. (2016). National Fire Protection Association 1710: Standard for the Organization and Deployment of Fire Suppression Operations, Emergency Medical Operations, and Special Operations to the Public by Career Fire Departments. $\quad$ Retrieved from https://www.nfpa.org/codes-and-standards/all-codes-and-standards/list-of-codes-and-standards/detail?code=1710

Onboard Informatics. (2018). Kingsville, Texas. Retrieved from http://www.city-data.com/city/Kingsville-Texas.html

Ozbay, K., \& Bartin, B. (2003). Incident Management Simulation. The society for modeling and simulation international, 79(2), 69-82. https://doi.org/10.1177/0037549703253494

Revelle, C., \& Hogan, K. (1989). The maximum reliability location problem and $\alpha$-reliable-center problem: Derivatives of the probabilistic location set covering problem. Annals of Operations Research, 18(1), 155-173.

https://doi.org/10.1007/BF02097801 
Schilling, D. A., Revelle, C., Cohon, J., \& Ezlinga, J. (1980). Some models for fire protection locational decisions. European journal of operation research, 5(1), 1-7. https://doi.org/10.1016/0377-2217(80)90067-3

U.S. Fire Administration. (2018). U.S. fire statistics. Retrieved from https://www.usfa.fema.gov/data/statistics/\#tab-4

Walker, W., \& Hausner, J. (1975). Determining the relation between fire engine travel times and travel distances in New York City. Operation Research, 23(4), 614-627. https://doi.org/10.1287/opre.23.4.614

\section{Copyrights}

Copyright for this article is retained by the author(s), with first publication rights granted to the journal.

This is an open-access article distributed under the terms and conditions of the Creative Commons Attribution license which permits unrestricted use, distribution, and reproduction in any medium, provided the original work is properly cited. 